Table 1 Patients seen at the Streatham Hill Sexual Health Clinic in London, UK on 24 and 31 December 2011

\section{Utilisation of community walk-in sexual health services over Christmas and New Year 2011}

In London many community-based sexual and reproductive health (SRH) services offer walk-in or appointment clinics on Saturdays. Some hospitalbased SRH services may be moving towards providing access over weekends as well. Traditionally, Christmas Eve and New Year's Eve, especially when they fall on a weekend, are seen as not very productive. The belief is that it may be difficult to get such clinics staffed but more importantly that women and men who use community services are unlikely to seek SRH care on Christmas Eve and New Year's Eve.

The Streatham Hill Sexual Health Clinic is a modern, fully integrated SRH service open 6 days a week including Saturdays. We decided in 2011 to offer a walk-in service on both Saturday 24 December and Saturday 31 December and monitored attendances.

In total 41 patients attended the walk-in service, 15 on Christmas Eve and 26 on New Year's Eve. We looked at the type of client attending and the activities undertaken and these are shown in Table 1.

Our experience suggests that walk-in SRH services offered on Christmas Eve and New Year's Eve are well utilised by patients and deliver an important public health function. The profile of patients attending was very similar to our normal clinic profile with $32 \%$ of attendees being men, $78 \%$ of attendees being local and $20 \%$ of attendees being aged $<24$ years. Some $51 \%$ of those attending were new to the service, suggesting that even on those days, when the assumption is that people are busy making arrangements for the festive period, sexual health needs still arise. It was interesting that $51 \%$ of attendees were seeking testing or treatment for sexually transmitted infections (STIs) and $49 \%$ were attending for contraception or gynaecological reasons. We treated eight patients for an STI and the full range of contraceptive methods was requested and provided during these two clinics.

\begin{tabular}{ll}
\hline Patients & $\begin{array}{l}\text { Percentage of } \\
\text { total (\%) }\end{array}$ \\
\hline Men & 32 \\
Lambeth and Southwark & 78 \\
residents & \\
Out of South London residents & 5 \\
Patients <24 years old & 20 \\
New patients & 51 \\
Contraception intervention & 42 \\
Reproductive health/ & 7 \\
gynaecology & \\
STI management/treatment & 51 \\
\hline
\end{tabular}

STI, sexually transmitted infection.

Ali Kubba, FRCOG, FFSRH

Lead Consultant, Community Reproductive and Sexual Health, Guy's and St Thomas' NHS Foundation Trust, London, UK: ali.kubba@lambethpct.nhs.uk

Competing interests None.

J Fam Plann Reprod Health Care 2012;38:205. doi:10.1136/jprhc-2012-100352 